\title{
HDI as a Measure of Human Development: A Better Index than the Income Approach?
}

\author{
Hasan Al-Hilani
}

\begin{abstract}
It has always been contentious how to measure human development. Contrary to simple income approach, multidimensional indices and constructs do provide us with better insight. One of the most popular indexes is Human Deveopment Index (HDI) that gives us information about country's education, health and longevity variables in addition to income. It has been established that, despite lots of shortcomings and critic, HDI has been able to present us with a different perspective to view and analyze development. Though, the issues regarding construct and formulation have been noticeable, HDI has improved a lot on these grounds since its formulation in early 1990s. It is believed that HDI is a credible index for providing us with an alternative view of human development. However, huge emphasis on it should be avoided for policy implementation and other development indicators should also be focused in addition to HDI.
\end{abstract}

Keywords: Human Development, Income Approach, Multi-dimensional Approach, HDI, Icome Component, Longevity Component.

\section{Introduction}

Human development is considered as one of the core areas of interest in development economics. There are several ways in which we can define human development. It is difficult to find a single coherent definition. However, the best way to explain it can be found in Sen's book 'development as freedom'. It says that human development can be regarded as expansion in people real freedoms that they enjoy. Focusing on human freedoms contrasts sharply with narrower views of development, such as identifying development with the growth of Gross National Product (GNP), with the rise in personal incomes, industrialization, with technological advance, or with social modernization. Sen $(1999, \mathrm{p} .1)$ said that, it is surely not a purpose to debilitate the contribution of these variables in accentuating welfare. Rather, it is simply argued that these variables are not sufficient conditions for development. We need to consider other dimensions too such as reach to fresh water, social and economic rights, or access to clothing and shelter etc. Similarly, Wilson and Woods (1982) also realized the importance of multi-dimension indices and measured to analyze the increasingly complex modern society on economic and social front.

Having discussed the complexity of defining development, it is even more challenging to measure human development. Several ways have been formulated and utilized to serve the purpose over the course history. Among the beginners, GDP per capita was a main variable as a proxy for human development. However, it was highly debated to use a measure of income as an alternative to human development. Consequently, we witnessed numerous other composite indices by various social scientists that were more credible and appropriate to measure development such as Child Development Index by 'Save the Children' NGO and Gender related Development Index (GDI) by UNDP. However, one of the most important indices among them is Human development index or HDI. It was proposed by Mahboob-ul-Haq in early 1990s on the basis of developmental concepts presented by Amartya Sen. It was from first UNDP's Human Development Report (HDR) that it started getting reported annually.

There has been found immense economic literature that deals with the various aspects of HDI. This paper attempts to gather all information available and represents conspicuously the pros of cons of HDI, as a measure of human development compared to simple income proxy such as GDP or GDP per capita. It will also be discussed, how HDI has responded to all criticism over time. The paper will not discuss other indices related to development, but some reference in the context of our study may be mentioned. The paper is arranged as follows: Section 1 - discusses the basic structure of HDI, section 2 - overviews the pros and cons together with literature review followed by changes made in HDI, in 2011, section 3 - discusses the comparison of income approach and HDI with some practical examples and lastly, section 4 - concludes the study with conclusions and recommendations.

\section{The Construct of HDI}

The construct of HDI has been explained fully in Human Development Report (1999, p.159-1960). The value ranges from 0 to 1 , where 0 implies no development and 1 mean full development. Normally, no country lies at the extremes and possesses a value between these two numbers. Though, the main structure is the same there has been some change in its construct since 2011, as elaborated in Human Development Report (2010) and 
here, we will discuss HDI index, as it is dealt with today. Contrary to simple income measure, HDI is a composite of three different components. Each of them is listed below with all the necessary detail.

\section{Standard of Living:}

The first component is the standard of living, and the proxy used to calculate it is the natural $\log$ of gross national income (GNI) per capita adjusted purchasing power in US dollars. GNI is different from GDP in that it is composed of the sum of all value added by resident producers in the economy plus product taxes plus receipts of primary income from abroad. Then, the GNI is normalized for each of the country by the formula:

$$
\text { Income Index }(\mathrm{II})=\frac{\ln (\mathrm{GNI})-\ln (\mathrm{min})}{\ln (\mathrm{Max})-\ln (\min )}
$$

Where $\ln (\max )$ and $\ln (\max )$ are natural logarithm for maximum and minimum GNI reported for that particular year.

\section{Education:}

The education level of each country can be calculated through the education index. Two variables; mean years of schooling and expected year of schooling are given one-half weight each. Adult literacy rate has been replaced by mean years of schooling and expected year of schooling has replaced combined enrollment ratio for primary, secondary and tertiary institutions. The formula for education index is

$$
\text { Education Index }(E I)=\left(\left(\frac{M Y S-M Y S_{M I N}}{M Y S_{\max }-M Y S_{M I N}}\right) \times\left(\frac{E Y S-E Y S_{M I N}}{E Y S_{M A X}-E Y S_{M I N}}\right)\right)^{\frac{1}{2}}
$$

Where, MYS is mean years of schooling and EYS is expected years of schooling.

\section{Health and Longevity:}

Longevity is measured by life expectancy at birth and normalized by the formula

$$
\text { Longevity }(L I)=\frac{L-L_{M I N}}{L_{M A X}-L_{M I N}}
$$

Where $L$ is life expectancy at birth for a country and min and max are minimum and maximum values for that particular year.

Finally, the HDI can be calculated by taking the geometric mean for all three measures as:

$$
=\sqrt[3]{E I \times I I \times L I}
$$

For example for year 2011, Norway tops the list with the HDI of 0.943, and the Republic of Congo is ranked at the bottom of the list composed of 183 countries with the HDI of 0.283 (Human Development Report 2011, p.138).

\section{Literature Review}

Since its construct, there has been found immense amount of economic literature relating to the motive, construct and reliability of HDI index. We found cases both for and against HDI index. Though, there may exist immense critic relating to the construct and form of the HDI; it is almost firmly accepted that it does provide with 'something more' than simple income approach such as GDP or GDP per capita.

Sagar and Najam (1999) evaluated the performance of HDI since its introduction in 1990s. They declare HDI to be a fruitful index, as it is a good step forward from unilateral income based approach. Booysen (2002) also discussed in detail why the multi-dimensional indices such as HDI are still considered a progress in explaining the development despite having issues with their constructs and statistical shortcomings. It is argued that though we can point out problems; these indices are useful in that they simplify complex measurement constructs and appeal for an attention for the variables included.

On the other hand, huge literature stressing to alter the existing construct for better results. For example, Hicks (1997) questioned the lack of distribution effects in HDI. HDI does expose country's performance in educational and health aspect, in addition to income, but it fails to incorporate how these dimensions are distributed among the people. The unique formulation in his Inequality-adjusted Human Development Index (IAHDI) is that it accommodates for education and health based inequality, in addition to income inequality; that is talk about too often. The results show that while accounting for inequality measures, some countries, such as Latin American countries, perform very badly on IAHDI scale but depict quite appreciating picture otherwise. On the other hand, though looking quite interesting on theoretical grounds the accurate collection of inequality data on educational and life expectancy dimensions remain quite challenging. Anyway, UNDP is now also reporting inequality based human development index, in addition to normal index, and we can interpret the human development from the lens of another perspective. Noorbaksh (1998) also suggested some alterations to the structure of HDI index. He criticized the scale effect in income and educational component of the index. It is argued that an additional dollar or an additional year of schooling is 
not as contributive at a high level of incomes or education level for people, as it is at a lower level of these variables. So, introducing diminishing marginal returns to both educational and income dimensions of HDI improve the reliability of the index and correct the extra optimistic pictures at a high level of component values. It is argued that this 'Modified Human Development Index (MHDI)' is a better indicator for not only to estimate any country's performance over time more accurately, but also when comparing any country in the context of rest of the world.

Sometimes, HDI provide us with an alternative way to look at the various aspects of the country's performance. Nissan and Niroomand (2005) compared the convergence and divergence phenomenon between income and other basic need variables such as HDI. The study divided the sample of 100 countries among the three groups high, medium and low on the basis of their income levels and HDI. The phenomenon of convergence was established for HDI especially in the case of poor countries whereas the income measure showed a divergent part. We observed an improvement in quality of life in low income countries over time. However, it was inferred that richer countries are still performing better despite the improvement in poor countries in the domains of quality of life. So, governments in developing countries are needed to allocate their funds more appropriately for better results in future.

Views relating to HDI lie in other extreme too. Certain studies completely dismiss the index on the basis that it fails to provide anything comprehensible and informative. Lind (2004) evaluated the reliability of the HDI index by analyzing the various feature of HDI. It is expressed that HDI is not a very suitable index for policy recommendations. It is determined that HDI sensitivity for each of its component variable is very different, and an equal increase in any one dimensions of it may bring in different changes in HDI. Further, it is argued that the HDI values for most of the developed countries are very high and close, and it is almost redundant to compare any two on the basis of HDI. Moreover, any developed country may show better results on HDI, despite being inferior on the ground, due to immense room for measurement or mathematical errors.

HDI may also introduce academia to extremely novel insights if used with some alternations. Another unique study is done by Harttgen and Klasen (2012) who took an initiative to analyze the micro-level distribution of HDI. HDI is a macroeconomic indicator by default and even adjusting it to inequality measures, as mention above, fails to incorporate micro level phenomenon. However, it is more knowledge and useful for policy purposes to investigate disparity in HDI among different economic and social groups including households. By calculating household level components of HDI, it was established that in some countries with low income equalities, we have witnessed high level of HDI inequality among different social groups. Similarly, the reverse result was also observed. The technique made it feasible to focus on intra-country level results and allowed a room for policy recommendations for various sections of the country.

\section{Answer to HDI Criticism: The 'New HDI'}

New modifications made in 2011 attempted to address some of the issues highlighted above. Three of total four dimensions of HDI were changed in 2010, and UNDP'S Human Development Report (2010) explained fully the rationale behind it.

Firstly, GNI per capita in \$US is used instead of famous GDP per capita. GDP was criticized to be used as a proxy of income dimension because it ignores huge amount of economic activity such as household work, subsistence farming (Klugman and Rodriguez 2011, p. 18). Moreover, it is firmly established that a person's average income may not be a good representation for its actual income. Similarly, literacy rate was replaced by mean years of schooling due to the fact that it has much greater discriminatory power. The literacy rate for most of the countries has increased drastically over past few years and hence, the range is not very satisfactory for the analysis (Klugman and Rodriguez 2011, p. 19). Additionally, gross enrollment ratio has been replaced by expected years of schooling for the estimation how many years a student is expected to take education if school enrollment rates stay constant. Similarly, now geometric mean has been used instead of arithmetic mean to calculate composite index as the arithmetic mean allowed for perfect substitutability among three dimensions (Desai 1999). Arithmetic mean implies that the deficiency in one dimension can be cancelled by improvement in another which is against the policy of developmental goals at all fronts. Moreover, the diminishing returns to income have also been incorporated by using logarithm of GNP per capita instead of simple form since early 2000s.

\section{Empirical Study}

After discussing all important issues regarding HDI on theoretical grounds, it would be imperative to investigate what empirics have to say about it. It would be interesting to see what results are obtained when we try to look at countries on the basis of income approach and how HDI alters them. There has been taken data of year 2011 and probed into the world ranking of 187 countries according to each of the method. Using GDP per capita as a representative variable for income approach, we observe that Luxembourg tops the list with the GDP per capita of \$113,533 (IMF, 2012). Similarly, Qatar, Norway, Switzerland follow the list with the GDP per capita of $\$ 98,329, \$ 97,255, \$ 81,161$ and $\$ 67,008$ respectively (IMF, 2012). On the other hand, while looking at 
the ranking on the basis of HDI, it is seen that Norway tops the list with HDI 0.943 followed by Australia, Netherlands, United States and New Zealand with the HDIs of 0.929, 0.910, 0.910 and 0.908 respectively (Human Development Report 2011, p. 38). HDI gives us a list that represents an alternative ranking on the basis of the index that is 'something' more than simple one-dimensional income approach. Now, it can be investigated how countries have performed on educational and longevity domains in addition to income, and another view has been provided to policy makers for better future aspirations.

After all discussions, it can be asked whether HDI ranking provide us with the list that is considerably different from income approach. If not, then has our all effort not been redundant in this regard? To resolve this inquiry, it would be beneficial to look for Pearson Rank correlation between GNI per capita and HDI index. For this, we used data from UNDP website on both of these variables. The table 1 below shows the major steps performed, and the final rank correlation has turned out to be about 0.948 .

Table 1: Pearson Rank Correlation between GNI per Capita and HDI Index

\begin{tabular}{|c|c|c|c|c|c|}
\hline & & $\begin{array}{c}\text { Human Development } \\
\text { Index (HDI) }\end{array}$ & $\begin{array}{c}\text { GNI per capita } \\
\text { rank minus } \\
\text { HDI rank (D) }\end{array}$ & D-Square & \\
\hline $\begin{array}{c}\text { HDI } \\
\text { rank }\end{array}$ & & Value & & & \\
\hline 1 & Norway & 0.943 & 6 & 36 & \\
\hline 2 & Australia & 0.929 & 16 & 256 & \\
\hline 3 & Netherlands & 0.910 & 9 & 81 & \\
\hline 4 & United States & 0.910 & 6 & 36 & \\
\hline 5 & New Zealand & 0.908 & 30 & 900 & \\
\hline 6 & Canada & 0.908 & 10 & 100 & \\
\hline 7 & Ireland & 0.908 & 19 & 361 & \\
\hline 8 & Liechtenstein & 0.905 & -6 & 36 & \\
\hline 9 & Germany & 0.905 & 8 & 64 & \\
\hline 10 & Sweden & 0.904 & 4 & 16 & \\
\hline 11 & Switzerland & 0.903 & 0 & 0 & \\
\hline 12 & Japan & 0.901 & 11 & 121 & \\
\hline & Hong Kong, China & & & & \\
\hline 13 & (SAR) & 0.898 & -4 & 16 & \\
\hline 14 & Iceland & 0.898 & 11 & 121 & \\
\hline 15 & Korea (Republic of) & 0.897 & 12 & 144 & \\
\hline$:$ & $:$ & $:$ & $:$ & $:$ & \\
\hline$:$ & $:$ & $:$ & $:$ & $:$ & \\
\hline$:$ & $:$ & $:$ & $:$ & $:$ & \\
\hline$:$ & $:$ & $:$ & -1 & 1 & \\
\hline 187 & Congo & 0.286 & & Rank & \\
\hline & & & $\mathbf{5 6 , 8 0 8}$ \\
\hline & & & & & \\
\hline & & & & & \\
\hline
\end{tabular}

Though, the correlation is very strong and positive, HDI does give us an alternative way to observe the phenomenon. At macro-level, the effort does not seem to be very optimistic, but it would be extremely interesting to study the cases of certain countries that perform quite differently at two indices. Table 2 shows the list of countries that exhibited maximum change in rankings when using these two different approaches. Guinea tops the list and its performance in GNI rankings is about 91 slots better than the HDI ranking. This result implies that Guinea is performing worse than 91 countries, additionally when education and longevity dimensions are included in addition to simple GNI per capita dimension. So, there is a clear signal for policy makers recommend policies for the betterment on these fronts. Similar inferences can be drawn for Kuwait and Botswana who loss huge places when ranked on the basis of HDI. The message for Georgia is quite interesting. Though, it lags behind from other countries when comparing with income indexes the results become reasonably optimistic when multi-dimensional approach is introduced. 
HDI as a Measure of Human Development: A Better Index than the Income Approach?

Table 2: List of Countries that Exhibited Maximum Change in Rankings

\begin{tabular}{|c|c|c|c|}
\hline $\begin{array}{c}\text { HDI } \\
\text { rank }\end{array}$ & COUNTRY & $\begin{array}{c}\text { Human } \\
\text { Development } \\
\text { Index (HDI) }\end{array}$ & $\begin{array}{c}\text { GNI per } \\
\text { capita rank } \\
\text { minus HDI } \\
\text { rank (D) }\end{array}$ \\
\hline 136 & Equatorial Guinea & 0.537 & -91 \\
\hline 63 & Kuwait & 0.760 & -57 \\
\hline 118 & Botswana & 0.633 & -56 \\
\hline 89 & Oman & 0.705 & -50 \\
\hline 123 & South Africa & 0.619 & -44 \\
\hline 106 & Gabon & 0.674 & -40 \\
\hline 148 & Angola & 0.486 & -38 \\
\hline 37 & Qatar & 0.831 & -36 \\
\hline 75 & Georgia & 0.733 & 36 \\
\hline
\end{tabular}

VI. Conclusion \& Recommendations

HDI has provided us with the multiple-dimensional framework to measure development compared to one dimensional income approach. There may present certain issues with the construct and form of HDI, but it does not debilitate its importance as one of the simple indices that provide us insight with some of the basic human freedoms. Moreover, lots of improvements have been made in the mathematical construct of HDI along time, and HDI has proved to be a much reliable index now compared to the time when it was first used.

On the other hand, it should be realized that it is just one index. Aid can be taken for policy and debate, but immense reliance on HDI can be misleading. There are some other good indexes formulated such as Gender Discrimination Indexes and Inequality Index etc, and they should all be considered fully before making any general policy recommendations. Similarly, there is a dire need for some new indices that can quantify the other human needs such as access to clean water and social and political rights to measure any country's performance fully.

\section{References}

[1]. Booysen, F. (2002). An Overview and Evaluation of Composite Indices of Development. Social Indicators Research. 59 (2), 115151 .

[2]. Desai, M. (1991). Human development: concepts and measurement. European Economic Review. 35(1) , 350-357

[3]. Harttgen, K. and Klasen, S. (2012). A House-hold based Human Development Index. World Development. 40 (5), 878-899.

[4]. Hicks, D.A. (1997). The Inequality Adjusted Human Development Index: A Constructive Proposal. World Development. 25 (8), 1283-1298.

[5]. International Monetary Fund.(2012). IMF Data and Statistics. Available: http://www.imf.org/external/data.htm. Last accessed 13 Jun 2012.

[6]. Klugman, J. , Rodriguez, F. and Choi, H (2011). The HDI 2010: New controversies and Old Critique. UNDP. 1-49.

[7]. Lind, N. (2004). Values reflected in the Human Development Index. Social Indicators Research. 66 (3), $283-293$.

[8]. $\quad$ Noorbaksh, F. (1998). A modified Human Development Index. World Development. 26 (3), 517-528.

[9]. Nissan, E. and Niroomand, F.. (2005). Convergence and Divergence of Basic Needs and Income: An International Comparison. The Journal of developing areas. 31 (1), 151-167.

[10]. Sagar, A.D. and Najam, A. (1998). The Human Development Index: A Critical Review. Ecological Economics. 25 (1), $249-264$.

[11]. Sen, A (1999). Development as Freedom. Oxford: Oxford University Press.

[12]. The World Bank. (2012). Data. Available: http://data.worldbank.org/. Last accessed 12 Jun2012.

[13]. UNDP (1990). Human Development Report. New York: Oxford University Press

[14]. UNDP (1990). Human Development Report. New York: Oxford University Press

[15]. UNDP (2010). Human Development Report. New York: Oxford University Press

[16]. UNDP (2011). Human Development Report. New York: Oxford University Press

[17]. Wilson, R.K. and Woods, C.S (1982). Patterns of world economic development. Melbourne: Longman Sorrett. 